A Novel Approach to Looking at the Role of Autonomy Support in the Development of Passion in Education

\author{
Tanya Chichekian, $\mathrm{PhD}$ \\ Department of Pedagogy \\ Université de Sherbrooke

\begin{abstract}
Sonia Rahimi, $\mathrm{PhD}$
Department of Social Psychology

Université du Québec À Montréal
\end{abstract} \\ Jérémie Verner-Filion, $\mathrm{PhD}$ \\ Department of Education \\ Université du Québec en Outaouais \\ Robert J. Vallerand, PhD \\ Department of Social Psychology \\ Université du Québec À Montréal
}


AUTONOMY SUPPORT AND PASSION IN EDUCATION

\section{A Novel Approach to Looking at the Role of Autonomy Support in the Development of Passion in Education}

There is a growing interest to uncover the various contributing factors to students' optimal functioning and self-growth, such as the development of a passion (Philippe et al., 2009; Vallerand et al., 2003; Vallerand, 2008). More specifically in the field of education, examining students' passion for a particular discipline seems to be a promising venue for many positive outcomes, such as engagement and creativity, sustained dedication, persistence, commitment, overall well-being, as well as positive affect among students (Bonneville-Roussy et al., 2011; Curran et al., 2015; Fredricks et al., 2010; Vallerand, 2015). It would thus be important to further study passion and its determinants in educational contexts to shed light on various potential outcomes at the academic, psychological, and social levels (Ruiz-Alfonso \& León, 2016). Despite the growing evidence demonstrating desirable outcomes among both teachers and students, research about developing a passion in the field of education is still very limited (Bonneville-Roussy et al., 2013; Ruiz-Alfonso et al., 2018).

One of the ways a student's passion can be developed is through the provision of autonomy support. Within an academic setting, research has demonstrated that teachers' autonomy support has provided evidence of students' persistence (Patall et al., 2018). Relatedly, parents' autonomy support has also been found to promote satisfaction of students' psychological needs and increased persistence in education (Ratelle et al., 2005). Thus, using autonomy support as a lens to study the development of passion would be important to understand the theoretical and practical implications involved in students' academic motivation and engagement (Patall \& Zambrano, 2019). Taken together, the present research sought to examine teacher and parental 
AUTONOMY SUPPORT AND PASSION IN EDUCATION

autonomy support as determinants regarding the potential development of passion for a specific discipline.

\section{Autonomy Support}

According to the Self-Determination Theory (SDT; Deci and Ryan, 1987, 2000; Ryan \& Deci, 2000), the importance of autonomy support is vital for optimal human functioning. In academic contexts, the theory of SDT outlines a striving for psychological need fulfillment as a drive that exists in all students, irrespective of their backgrounds (Reeve, 2006). Moreover, in autonomy-supportive settings, adults view children as autonomous individuals with their feelings and preferences and favor self-determinedness in children by respecting their ability to make their own choices. Autonomy supportive environments have also been shown to relate directly with passion in a variety of contexts and promote positive or prevent negative outcomes among adults at work (e.g., with employers, Slemp et al., 2021) and among athletes (e.g., with coaches, Bentzen et al., 2016). For students, however, such autonomy support can be derived from various sources, including teachers (Patall et al., 2018) and parents (Ratelle et al. 2012), each of which will be outlined below.

Teacher autonomy support (TAS). Teachers' motivational style and autonomy support are key ingredients to fostering students' motivation and engagement (Reeve, 2006). If teachers succeed in supporting students' intrinsic motivation by staying attuned to their needs and interests and by providing opportunities for them to manifest their preferences, it is expected for students to experience high levels of autonomy. On the contrary, if teachers provide more of a controlling learning environment through extrinsic rewards or pressuring language, it is expected that less favorable outcomes will emerge such as disengagement and external regulation. As 


\section{AUTONOMY SUPPORT AND PASSION IN EDUCATION}

such, teachers' motivational style can be described on a continuum of quality, ranging from highly controlling to highly supporting autonomy.

SDT's framework is structured such that students' inherent psychological needs as well as their interests, preferences, and values, are either supported or hindered by classroom conditions, such as autonomy-supportive learning environments. For example, in such contexts, there is an effort from teachers to communicate value and rationale for given academic activities, acknowledge students' positive and negative affect, and allow them a certain freedom to express their intrinsic motivation (Cheon et al., 2020). The beneficial outcomes related to autonomysupport from teachers have been well documented and include a range of outcomes such as autonomous self-regulation and course performance (Black \& Deci, 2000), engagement and persistence (Patall et al. 2018), intrinsic motivation (Cheon et al., 2020), and increased positive emotions (Oriol-Granado et al., 2017). Consequently, autonomy-supportive learning environments are conducive to students' ability to act out of free choice, thus rendering a certain degree of control to students.

Parental autonomy support (PAS). According to SDT, one of the important dimensions of parenting is autonomy support, alongside structure and involvement. Ratelle et al. (2012) found that keeping a distinction between different sources of autonomy support, such as from parents, friends, and romantic partners, is important as they each provide distinctive functions and outcomes among different age groups. Parents, for example, nurture a specific type of support leading to autonomy-enhancing environments, namely by acknowledging their children's perspectives, encouraging them to experiment, providing occasions to make their own choices, and minimizing controlling language (Vasquez et al., 2015). Findings from other studies also 


\section{AUTONOMY SUPPORT AND PASSION IN EDUCATION}

underscore the capital role that PAS can play in children's appraisals of failure, coping, and engagement, as well as academic achievement (Raftery-Helmer \& Grolnick, 2018). Thus, when parents support students' autonomy in problem-solving, for instance, students tend to perceive failures as challenges and not necessarily setbacks.

Additionally, Ratelle et al. (2005) showed that perceived PAS also predicted students' persistence partly through their levels of autonomy and competence. Students' competence and feelings of autonomy partially mediated the relationship between their perceptions of PAS and educational persistence in a scientific program. In sum, PAS has been found to significantly and positively correlate to a multitude of academic consequences, namely academic adjustment, persistence, achievement, self-determination, career orientations, and overall subjective wellbeing (Guay et al., 2013).

Thus, autonomy-supportive environments (e.g., as created by teachers or parents) foster the development of adaptive outcomes for students, including motivational factors such as increased intrinsic motivation, interest, and engagement (Black \& Deci, 2000; Patall et al. 2018). As such, students with autonomous motivation perform better in their courses and experience more selfgrowth and potential for optimal functioning. However, the associations between TAS and PAS together have never been directly associated with passion. Thus, the ultimate goal of the present research was to examine the role of TAS and PAS on college students' passion for science.

\section{Dualistic Model of Passion (DMP)}

According to The Dualistic Model of Passion (DMP; Vallerand et al., 2003), passion is defined as a strong drive, love for, and engagement toward a self-defining activity, so much so that the activity forms a central part of a person's identity (Vallerand 2010, 2015, 2016). Passion can manifest itself in various contexts and is distinguished from other closely related constructs 


\section{AUTONOMY SUPPORT AND PASSION IN EDUCATION}

(e.g., interest) through the internalization process of the activity into one's identity. Vallerand et al. (2003) conceptualized passion qualitatively into two distinct types: harmonious passion (HP) in which a balanced relationship is established with a beloved activity, and obsessive passion (OP) which involves more of a conflicted relationship with the beloved activity. Passion can also be considered quantitatively, in terms of how much passion a person can have towards a specific activity. Academic passion, for example, can vary in both quantity and quality (Vallerand, 2010), thus creating the possibility to examine dual stability over time (Schellenberg \& Bailis, 2015).

These two types of passion diverge based on how the passionate activity has been internalized into a person's identity. With HP, the activity is internalized into the person's identity autonomously, since it is considered important to the person, without any contingencies attached to it (Vallerand et al., 2003). The pursuit of the activity significantly occupies the person's time and efforts, but at the same time does not overpower one's identity and other aspects of one's life since the locus of control remains in his or her hands. The person can thus persist in a flexible way (Author 1) and maintain a balance between the activity and other life domains (Bonneville-Roussy et al., 2013). For example, a student may spend hours studying their favorite subject, yet he or she would have the ability to step away from studying for a few moments to enjoy some leisurely time without feeling guilty about it.

With OP, the activity is internalized in a controlled manner in which the person experiences the very same levels of drive and desire to engage in a loved activity, but no longer possesses the same control over the extent of his or her engagement (Vallerand et al., 2003). In this way, the internal pressure felt by the individual to continue engaging in the activity leads to rigid persistence (Author 2) and, consequently, other unfavorable consequences. For example, the same student devoting hours of study in their favorite course 


\section{AUTONOMY SUPPORT AND PASSION IN EDUCATION}

might forgo any leisurely time or, if he or she does end up stepping away from studying, he or she would feel a substantial amount of guilt. In this case, there are contingencies related to the activity, stemming from either intra or interpersonal sources. For instance, an individual might enjoy an activity yet feel compelled to engage in it uncontrollably, due to desires of social acceptance, self-esteem, or performance (Philippe et al., 2009).

Passion-based outcomes in education. In educational research, it has generally been found that both HP and OP are positively linked to perseverance and the pursuit of excellence in one's studies (Vallerand, 2010, 2015, 2016), but tend to vary significantly in other outcomes (BonnevilleRoussy et al., 2013; Philippe et al., 2009). Contrary to OP, HP is linked to more efficient learning strategies, more adaptive goal-setting (Bonneville-Roussy et al., 2013; Fredricks et al., 2010; Schellenberg \& Bailis, 2015), and higher concentration levels during task engagement (Vallerand et al., 2003). For example, in a study with high-school students, Ruiz-Alfonso and León (2017) found that HP for one's studies positively predicted motivation to learn. Subsequently, it also predicted actual math performance by triggering adaptive cognitive processes such as deep learning strategies and epistemic curiosity toward the learning materials. Other studies focusing on longterm performance have used achievement goals (Elliot \& Harackiewicz, 1996) to demonstrate how students who were passionate about their studies (Vallerand et al., 2007, Study 2), music (Bonneville-Roussy et al., 2011), or sports (Vallerand et al., 2008, Study 2) engaged in processes leading one to commit to deliberate practice. Moreover, HP is associated with well-being, life satisfaction, positive affect, and the experience of flow during an activity, while also acting as a buffer against anxiety, depression, and burnout (Bonneville-Roussy et al., 2013; Carpentier et al., 2012; Philippe et al., 2010; Ruiz-Alfonso et al., 2018; Vallerand et al., 2003; Zhao et al., 2015). Indeed, research reveals that HP can also lead to important outcomes in other spheres of one's life 


\section{AUTONOMY SUPPORT AND PASSION IN EDUCATION}

such as positive relationships and psychological well-being (e.g., Bonneville-Roussy et al., 2011, 2013; Author 3).

Whereas HP is linked to positive outcomes both during and outside of an activity, OP tends to lead to an imbalance between the passionate activity and other life goals (Boiché \& Caudroit, 2019; Vallerand et al., 2008, 2010), thereby leading to negative outcomes in other life spheres such as lower well-being, burnout, and rumination (Curran et al., 2015; Philippe et al., 2009, 2010; Saville et al., 2018; Vallerand et al., 2010), lower life satisfaction, absence of flow and positive affect, and generally compromised levels of well-being (Bonneville-Roussy et al., 2013; RuizAlfonso et al., 2018; Vallerand et al., 2003). Despite leading to positive outcomes in terms of performance within the passionate activity, OP also seems to lead to outcomes such as guilt, frustration, anxiety (Mageau et al., 2009; Author 4). Furthermore, college students' obsessive passion for their studies has been found to adversely impact their health through excessive drinking habits, sleep deprivation, and disordered eating (Bureau et al., 2017). Thus, it would appear that with $\mathrm{OP}$, one would tend to persist in the activity even when deemed inappropriate to continue (Stenseng, 2008; Vallerand et al., 2003).

Overall, the experience of HP vs. OP leads to different implications in educational contexts (e.g., flow and positive emotions vs. burnout and negative emotions, respectively). Thus, while the present research sought to examine teacher and parental autonomy support as potential determinants of passion, it was expected that varying levels of perceived autonomy support would have a differential effect on HP and OP.

\section{Autonomy Support and Passion}

Although no studies have examined the direct associations between TAS and PAS together alongside passion, several studies have looked at such relationships individually. In concordance with SDT, teachers who adopt an autonomy-supportive instructional style can enhance their 


\section{AUTONOMY SUPPORT AND PASSION IN EDUCATION}

students' academic persistence, as well as their development of passion (Ruiz-Alfonso et al., 2018). Since TAS allows students to choose their academic activities freely without any contingencies, it is much more likely that students will fully integrate a given academic activity into their identities as a result of willful engagement. Moreover, research has shown that students of autonomy-supportive teachers display more HP compared to those who had controlling professors and were more prone to OP (Bonneville-Roussy et al., 2013).

Similarly, TAS has also been found to predict greater need satisfaction, engagement, and well-being among many other positive outcomes (Patall \& Zambrano, 2019). Fredricks et al. (2010) found that teachers who included the freedom of choice alongside providing feedback and promoting active learning engendered a more stimulating learning environment and contributed to passion development over time. Moreover, students from autonomy-supportive classrooms experienced enhanced academic self-regulation, as well as overall psychological adjustment, enhanced learning, higher performance, and persistence (Patall et al., 2018). Given the many positive outcomes deriving from TAS, it is worthwhile pursuing research about the relationship between TAS and passion as most studies have thus far only suggested that teachers are either mostly indifferent or controlling in their classrooms (Patall \& Zambrano, 2019). In addition, results from Mageau et al. (2009) showed a similar pattern of findings in which individuals with parents who are autonomy supportive were more likely to experience HP versus OP. However, more recent work by Toth-Kiraly et al. (2021) showed that autonomy granting from parents positively predicted OP, but the authors do emphasize that autonomy granting in such contexts referred more to students' freedom and parents" "laissez-faire" attitudes compared to the more structured format of autonomy support outlined in SDT. Although the evidence concerning the 


\section{AUTONOMY SUPPORT AND PASSION IN EDUCATION}

role of PAS in passion is limited, the goal of the current research about autonomy support from teachers and parents is to provide evidence that both forms of autonomy support do play a different role in students' passion (HP and OP) within academic contexts.

\section{The Present Research}

The purpose of the present research was to determine the role of low and high levels of teacher and parental autonomy support in college students' passion (HP and OP) for science. Traditionally passion has been assessed in a two-dimensional fashion in which participants are assumed to have a predominant type of passion (HP and OP). However, in the present research, we adopted the $2 \times 2$ model of dispositional perfectionism as proposed by Gaudreau and Thompson (2010) when examining the relationships between autonomy support and passion. The 2 x 2 model in Gaudreau and Thompson's study (2010) presented dispositional perfectionism by assessing two factors of perfectionism called pure evaluation concerns and pure personal standards. However, they assessed these two types in a 2 X 2 model in which four groups were created including non-perfectionists (low on both types of perfectionism), pure evaluation concerns perfectionists (high on evaluation concern, low on personal standards), pure personal standards perfectionists (high on personal standards, low on evaluation concerns), and mixed perfectionists (high scores on both types of perfectionism). While previous research may have only referred to pure evaluation vs. pure personal standards perfectionism, they were able to examine compound effects of having multiple types of perfectionism vs. no perfectionism alongside the other types. Their research showed that each of the four subtypes of perfectionism was differentially related to various outcomes (e.g., positive and negative affect), thus providing a more holistic view of the construct. In the present study, we adopted a similar approach and used TAS and PAS to create four subgroups that reflected low vs. high levels of autonomy support from each respective source. As such, this study will be the first to apply the $2 \times 2$ 


\section{AUTONOMY SUPPORT AND PASSION IN EDUCATION}

model with testable hypotheses in the context of postsecondary education.

Based on the $2 \times 2$ model of dispositional perfectionism (Gaudreau \& Thompson, 2010), we assumed that both forms of autonomy support would be present to varying degrees within each individual rather than differences that lie within the dimensions themselves. By focusing on the within-person combinations of low and high levels of TAS and PAS, a more meaningful level of analysis could take place to differentiate the relationship between the two types of autonomy support and passion. As such, HP and OP could be examined based on the quantitative scores of teacher (TAS) and parental (PAS) autonomy support at four distinct levels, while also delineating ways to examine hypotheses in the absence of a significant interaction. These groups included: (1) Low Support (LS) for those with low levels of both TAS and PAS, (2) Pure TAS (PT) for those with high levels of TAS and low levels of PAS, (3) Pure PAS (PP) for those with low levels of TAS and high levels of PAS, and (4) Dual Support (DS) for those with high levels of both TAS and PAS (Table 1).

These four levels are based on the relative strength (i.e., low or high) of both TAS and PAS. First, we delineated Low Support (LS) to refer to low levels of both TAS and PAS as reflected by low levels of both HP and OP. Second, we inferred high levels of TAS combined with low levels of PAS form the basis of Pure TAS (PT). Those with a Pure TAS were expected to have internalized a passionate activity in somewhat of a less balanced way given that other academic and more uncontrollable factors may have been at play (e.g., academic achievement for competitive university admissions). Third, high levels of PAS combined with low levels of TAS defined the characteristics of Pure PAS (PP). Contrary to Pure TAS, those with a Pure PAS were expected to internalize a passionate activity in a way that displayed many of the aspects found in HP, which included a sense of balance when pursuing a passion. Fourth and finally, the Dual Support (DS) described the presence of high levels of both TAS and PAS as a means to foster the 


\section{AUTONOMY SUPPORT AND PASSION IN EDUCATION}

development of both forms of passion toward an activity. With DS, individuals were expected to acknowledge that a passionate activity may be harmonious while at times becoming also obsessive depending on the conditions that were present in a specific context.

Overall, the present research aimed to answer the following questions:

1. What is the impact of no perceived teacher and parental autonomy support on college students' passion for science?

2. What are the unique effects of perceived teacher and parental autonomy on the distinct forms of passion among college students in a science program?

3. What is the impact of dual autonomy support on college students' passion for science? Specifically, we wanted to test the extent to which college students displayed HP and OP toward their science courses depending on the extent to which they perceived different forms of autonomy support. Consequently, we compared six different combinations of TAS and PAS and their effects on passion (HP and OP):

1. Between Low Support (LS) and "Pure" Teacher (PT);

2. Between Low Support (LS) and "Pure" Parent (PP);

3. Between Low Support (LS) and Dual Support (DS);

4. Between "Pure" Teacher (PT) and "Pure" Parent (PP);

5. Between "Pure" Teacher (PT) and Dual Support (DS);

6. Between "Pure" Parent (PP) and Dual Support (DS).

Based on past findings using similar approaches (e.g., Gaudreau \& Verner-Filion, 2012, Schellenberg et al., 2018), we formulated the four following hypotheses:

- H1: Low Support (LS) would be associated with the lowest levels of HP and OP.

- H2: Pure TAS (PT) would be associated with better outcomes than Low Support (LS, H1) and with poorer outcomes compared to Dual Support (DS, H4) for both forms of passion. Higher OP was also expected compared to Pure PAS (PP, H3). 
AUTONOMY SUPPORT AND PASSION IN EDUCATION

- H3: Pure PAS (PP) would be associated with better outcomes than Low Support (H1) and with poorer outcomes compared to Dual Support (DS, H4) for both forms of passion. Lower OP was also expected compared to Pure TAS (PT, H2).

- H4: Dual Support (DS) would be associated with better outcomes for both HP and OP compared to Pure TAS (PT) or Pure PAS (PP).

By considering the presence of both TAS and PAS, we can focus on a novel approach when examining the role of autonomy support in the development of passion in education. We know from past research that similar dual approaches have shed light on novel questions and hypotheses (e.g., Gaudreau, 2012 on perfectionism, Vallerand, 2015 on passion) and we hope to test a similar approach with autonomy support. Based on a meta-analytical review from Curran et al. (2015) about the psychology of passion and a review from Patall \& Zambrano (2019) about autonomy-supportive practices in education, we expected that Pure PAS (high levels of PAS combined with low levels of TAS) would be associated mostly with HP. Moreover, extrapolating from findings in research studying passion toward multiple activities (Schellenberg \& Bailis, 2015), we expected that a Dual Support would be associated with higher levels of HP compared to Pure TAS. Finally, because those who experience OP still engage in activities that they perceive as producing negative experiences (Vallerand, 2015), we expected LS to be associated with the lowest levels of both HP and OP.

\section{Method}

\section{Participants and Procedures}

Participants consisted of 970 (376 males, 594 females) students recruited from six different public colleges in Eastern Canada. Students were enrolled in different preuniversity science programs, specifically in Health $(\mathrm{n}=589)$, Pure and Applied $(\mathrm{n}=302)$, and others such as environmental and computer science $(n=75)$. Four students did not report their program. The 


\section{AUTONOMY SUPPORT AND PASSION IN EDUCATION}

sample included students from Year $1(n=424)$, Year $2(n=494)$, and Year $2+(n=25 ; n=27$

did not report). A survey was administered by a trained research assistant in classrooms and online through the college's portal in the Fall and Winter semesters (different samples). Before distributing the survey, a presentation was made outlining the main research objectives and the process of informed consent. Those who agreed to participate in the research study were asked to complete scales that measured passion, perceived autonomy support from teachers and parents, as well as other scales related to academic outcomes. We report here only on the Passion and Perceived Autonomy Support scales.

\section{Measures}

Autonomy support. The Perceived Autonomy Support Scale (Mageau et al., 2009) was adapted to measure students' perceived autonomy support with three items used to measure freedom of choice with respect to both teachers (e.g., "When making decisions in class, my science teachers consider my point of view even when it is different from theirs") and parents (e.g., "When making decisions about my scientific activities, my parents consider my point of view even when it is different from theirs") autonomy support. Cronbach alphas for TAS and PAS were respectively .72 and .76 .

Passion. Participants were asked to complete scales that measured both HP and OP for science. Overall passion levels were measured using the Passion Scale (Vallerand et al., 2003), which included three subscales: HP (6 items; e.g., "This activity is in harmony with the other activities in my life"), OP (6 items; e.g., "I have difficulties controlling my urge to do my activity"), and the passion criteria (4 items; e.g., "I spend a lot of time doing this activity"). Cronbach's alpha for HP was .85 and .80 for OP.

\section{Data Analysis}

Prior to any analysis, we removed outliers that mapped on to two or more of the following 


\section{AUTONOMY SUPPORT AND PASSION IN EDUCATION}

indicators: Leverage, Cook's, or Mahalanobis distances. This resulted in a final sample of $\mathrm{n}=$ 955. Analyses were conducted using R version 3.6.5 and SPSS. We analyzed two linear regression models with TAS and PAS as predictors, gender as a covariate, and HP and OP as dependent variables.

As an initial step, we examined the significance of an interaction term between TAS and PAS before testing main effects only (Cohen et al., 2003). In the presence of a significant interaction, we would calculate the predicted values of HP and OP calculated at 1SD and +1SD of TAS and PAS, respectively, and use them as planned contrasts (along with the 95\% CI of the predicted values) to compare outcomes (Gaudreau \& Thompson, 2010). In the absence of a significant interaction, we would run a multiple regression without the interaction term to increase parsimony and so that TAS will not remain conditioned at the mean value of PAS (or vice-versa), including the non-significant interaction term between PAS and TAS. Results will thus be interpreted using four simple slopes (main effects) of TAS and PAS to make statistical inferences about the four hypotheses and demonstrate that a significant interaction is not necessary to examine hypotheses based on the $2 \times 2$ model (Gaudreau, 2012).

\section{Results}

Correlations and descriptive statistics are displayed in Table 2. TAS and PAS were significantly correlated $(r=0.07, p=.039)$, whereas HP was significantly associated with both TAS $(r=.28, p<.01)$ and PAS $(r=.16, p<.01)$, and OP was significantly associated with TAS $(r=.20, p<.01)$ but not with PAS $(r=-.02, p>.05)$. All items were presented in a Likert format, ranging from 1 ("I totally disagree") to 5 ("I totally agree").

A hierarchical regression was performed to predict HP and OP. Significant differences were observed between males and females in all variables, therefore we included gender as a covariate in our models. Gender was entered in the first step, followed by the centered scores of 


\section{AUTONOMY SUPPORT AND PASSION IN EDUCATION}

TAS and PAS, and the interaction term in the third step. Results indicated that the interactive effect was not significantly associated with HP $(\mathrm{B}=-.035, t=-1.034, p>.05, \Delta F(1,950)=$ $1.069, p=.30)$ and $\mathrm{OP}(\mathrm{B}=-.023, t=-0.714, p>.05, \Delta F(1,950)=0.509, p=.48)$, after controlling for gender and the main effects of TAS (HP: $\mathrm{B}=0.237, t=8.59, p<.05$; OP: $\mathrm{B}=$ $0.166, t=6.12, p<.01)$ and PAS (HP: $\mathrm{B}=0.150, t=5.24, p<.05 ; \mathrm{OP}: \mathrm{B}=-0.018, t=-0.64, p>$ $.05)$.

After dropping the non-significant interaction term from both models, a multiple regression with uncentered scores were conducted to estimate the main effects of TAS and PAS. The first step was to test the structure of our scales through a CFA. The models for HP (autonomy support from parents, teachers, and harmonious passion) and OP (autonomy support from parents, teachers, and obsessive passion) had a good fit to the data if we added positive covariance links between some items within the same subscale. The fit of the HP model was: $\chi^{2}=73.394$, df $=45$, $p=.005, \mathrm{CFI}=.991, \mathrm{TLI}=.987, \mathrm{RMSEA}=.027[.015, .038], \mathrm{SRMR}=.028$ and the one for OP was $\chi^{2}=100.200, \mathrm{df}=47, p=.000, \mathrm{CFI}=.980, \mathrm{TLI}=.972, \mathrm{RMSEA}=.036[.026, .045], \mathrm{SRMR}$ $=.032$.

Second, the models testing for the main effects of both sources of autonomy support on HP were significant $(\mathrm{F}(3,951)=38.96, p<.001)$ and explained $11 \%$ of variance with an intercept of 2.15. TAS and PAS were positively and significantly associated with HP $(B=0.237$, $\mathrm{b}=.028, t=8.525, p<.001$ and $B=0.150, \mathrm{~b}=.030, t=4.958, p<.001)$. The models testing for the main effects of both sources of autonomy support on OP were significant $(\mathrm{F}(3,931)=19.54$, $p<.001)$ and it explained $6 \%$ of variance with an intercept of 2.088. TAS was positively and significantly associated with OP $(B=0.165, \mathrm{~b}=.028, t=5.929, p<.001$. PAS was not significantly associated with OP $(B=-0.018, \mathrm{~b}=.030, t=-0.589, p=.556)$.

Third, predicted values of HP and OP were calculated across low (-1SD) and high 
$(+1 \mathrm{SD})$ values of TAS $(M=3.20, S D=0.91)$ and PAS $(M=4.25, S D=0.83)$. Figures 1 and 2 depict the scenario in which the four hypotheses can be tested with the main effects of the two predictors using statistical approaches such as multiple regression despite a non-significant interaction between TAS and PAS. The following linear regression equations were used to calculate the predicted values as per Gaudreau (2012):

(1) Y of Low Support $($ LS $)=$ Intercept $+($ B TAS. Low TAS $)+($ B PAS. Low PAS $)$.

(2) $\mathrm{Y}$ of Pure TAS $(\mathrm{PT})=$ Intercept $+($ B TAS. High TAS $)+($ B PAS. Low PAS $)$.

(3) $\mathrm{Y}$ of Pure PAS $(\mathrm{PP})=$ Intercept $+($ B TAS. Low TAS $)+($ B PAS. High PAS $)$.

(4) $\mathrm{Y}$ of Dual Support (DS) = Intercept $+($ B TAS. High TAS $)+($ B PAS. High PAS $)$. The standardized effect sizes (Cohen's d) were roughly estimated using the SD of the dependent variable and the predicted values of each level of autonomy support. Cohen's $d$ is the appropriate effect size measure if two groups have similar standard deviations and are of the same size. There were significant differences between all predicted values for HP and mostly for OP as well, except between PT-DS and between PP-LS (see Table 3).

Results showed that having support from both sources, compared to all other possibilities, was related to higher levels of HP. Second, it seems when perceived autonomy support from teachers was high and that from parents was low, students displayed higher levels of HP compared to those who perceived higher levels of autonomy support from parents. This was expected given that the relationship between teachers and students is contextualized in a specific and similar domain (i.e., science). Third, when perceived autonomy support from parents was high and that from teachers is low, students displayed higher levels of HP compared to low support from both sources. Fourth, low support from both sources was related to the lowest levels of HP. Finally, when perceived autonomy support from parents was high and that from teachers was low or when there was low support perceived from both sources, students displayed the lowest levels of OP. 


\section{Discussion}

The purpose of the present research was to test the role of the teacher (TAS) and parental (PAS) autonomy support in college students' harmonious (HP) and obsessive passion (OP) for science. Four distinct levels were identified based on low and high levels of autonomy support: Low Support (LS) for those with low levels of both TAS and PAS, Pure Teacher (PT) for those with high levels of TAS and low levels of PAS, Pure Parent (PP) for those with high levels of PAS and low levels of TAS, and Dual Support (DS) for those with high levels of both TAS and PAS. We tested and compared six different combinations of the extent to which TAS and PAS were perceived as having an effect on college students' passion (HP and OP) for science.

First, based on the $2 \times 2$ model, we posited that LS would be associated with the lowest values for both HP and OP (H1). This is because to have any form of effect on passion, students would need to perceive some degree of autonomy support conveyed by their teacher during class or by their parents at home. Second, we also posited that experiencing high levels of just TAS (H2) or just PAS (H3) would lead to higher values in both forms of passion compared to LS, but to lower values compared to DS. Third, we expected students to experience lower values of OP during the presence of PAS compared to TAS. Finally, we anticipated that students with DS would display higher values for HP and OP compared to any other combination of autonomy support (H4). Overall, the results demonstrated that the absence of autonomy support seemed to hinder the development of HP, while a Dual Support seemed necessary to experience higher values of HP. Additionally, it seems that TAS and PAS independently and positively influence the development of HP, whereas TAS alone (but not PAS) also positively influences the development of OP. Furthermore, Figures 1 and 2 demonstrated that PAS was associated with lower values of OP and higher values of HP when perceived TAS was low. The present findings lead to several implications.

A first implication of the present findings is that teacher and parental autonomy support do 


\section{AUTONOMY SUPPORT AND PASSION IN EDUCATION}

have an effect on both forms of passion. Our findings showed that PAS was positively correlated with HP, while TAS was positively correlated with both HP and OP. These findings provide preliminary evidence regarding the importance of autonomy-supportive environments in fostering HP. Indeed, the present findings extend past writings (e.g., Patall et al., 2018; Ratelle et al. 2012) by empirically demonstrating a novel approach to assessing the role of autonomy support in the potential development of passion as described under the DMP. Recent research shows that engaging in an activity that is nested in an autonomy-supportive environment leads to positive outcomes related to freedom in exploring the activity, displaying creativity, and experiencing positive affect (Cheon et al., 2020). In the present research, students' perceptions of high and low levels of both teacher and parental autonomy support differentially influenced their passion for a discipline. Specifically, students' perceptions of dual support rendered the highest means for HP and low support from both sources produced the lowest levels of HP, thus confirming $\mathrm{H} 1$ and $\mathrm{H} 4$. On the other hand, students' perceptions of dual support rendered higher means for OP compared to low support from both sources. This implies that students' perceptions of teacher and parental autonomy support play a differential role in academic contexts which in turn influences the way they feel passionately toward a specific discipline.

A second implication is that an independent main effect in autonomy-supportive behaviors seems to play an important role in students' passion for a discipline. According to past research, when students perceive teachers supporting their perspectives and initiatives, they tend to show more interest and engagement toward their courses (Patall et al., 2018), as well as an enhanced academic persistence (Bonneville-Roussy et al., 2013). Similarly, in the present research, students who demonstrated only high levels of TAS also displayed higher levels of HP compared to those with low levels of TAS, thus confirming H2. Conversely, students with the highest predicted values of OP also displayed high levels of TAS. It seems that teacher autonomy 


\section{AUTONOMY SUPPORT AND PASSION IN EDUCATION}

support alone influences students' passion (harmonious and obsessive) for a specific discipline depending on the extent to which it provides freedom of choice (Cheon et al., 2019). In the present research, parental autonomy support also played a role in students' passion, and this was especially important in the absence of teacher autonomy support. For example, OP levels were high when TAS was high, while those from parents were low. On the other hand, OP levels were lowest when teacher autonomy support was low, while those from parents were high, thus confirming H3. Consequently, perceived low support from both parents and teachers was not as ideal as having only support from parents to keep OP at the lowest levels.

A third and final implication is that dual support defined the optimal context in which students could develop passion in a healthy manner. Learning environments with limited pressure and control exercised by teachers and parents (Mageau \& Vallerand 2003; Mageau et al., 2009; Ratelle, 2012) highlight the distinct but also relative contribution of autonomy support to students' passion toward a discipline. Moreover, using a more active approach to autonomy support which is in line with the theoretical tenets of SDT allowed us to transpose it onto a $2 \times 2$ model and examine passion through six different combinations with more diverse outcomes. This is contrary to the more passive approach in which autonomy granting is perceived as being too permissive and characterized by complete freedom of choice and a somewhat lack of structure and, consequently, more prone to being conducive to OP (Toth-Kiraly et al., 2021). In sum, assessing both forms of autonomy support using the 2 × 2 model (Gaudreau, 2012) provided a novel approach to examining the role of TAS and PAS and how they are associated with passion. Overall, the present results demonstrate the relationship between autonomy support and passion based on a continuum as opposed to more clear-cut quadrants of low and high levels using cutoff values. Moreover, by investigating within-person groupings (e.g., Franche \& Gaudreau, 2016), the present findings demonstrated that not only are TAS and PAS 


\section{AUTONOMY SUPPORT AND PASSION IN EDUCATION}

important for the development of passion, having dual support was associated with more functional consequences for both HP and OP.

\section{Limitations and Future Directions}

This study was conducted under some limitations which should be considered when interpreting the current findings. First, this was a correlational design and, consequently, no causal inferences can be warranted. Nevertheless, the same methodological process was replicated as others (e.g., Gaudreau \& Thompson, 2010; Gaudreau \& Verner-Filion, 2012; Schellenberg et al., 2018) who also relied on a 2 x 2 model to interpret their research findings. Second, all measures in this study were self-reported by the students (i.e., perceived autonomy support). Consequently, future research is needed to replicate the present findings either with more objective assessments of autonomy support or qualitative data such as individual interviews. Third, the participants in this study were relatively homogeneous (i.e., relatively same age group and same program). It would thus appear important to replicate the present findings with other student populations from other disciplines (outside of science). Finally, because this sample included subjects who were older than high school students, possibly better disciplined compared to younger students, and also with a somewhat developed autonomy, parents may have provided them with more freedom of choice.

\section{Conclusion}

In conclusion, the present research highlights the important role that teachers' and parents' autonomy support plays with respect to the development of students' passion for science.

Overall, by examining autonomy support and passion using the $2 \mathrm{X} 2$ model, the present findings illustrated that having low autonomy support from teachers and parents impedes students' development of HP while experiencing both forms of support was found to result in high levels of HP. Moreover, parental autonomy support played a critical role for OP. With high levels of 


\section{AUTONOMY SUPPORT AND PASSION IN EDUCATION}

perceived parental autonomy support and low levels of teacher autonomy support, the predicted values for OP were at their lowest.

These findings have both methodological and practical implications. The present research demonstrates the importance and practicality of looking at variables more dynamically (e.g., low and high levels of autonomy support as being relative to the sample average) to ascertain conclusions. Although we applied the $2 \times 2$ model using multiple regressions with observed variables (Gaudreau \& Thompson, 2010), it is a flexible approach that can easily be used in more complex analyses involving mediation or multilevel analyses. Possible future directions of research could be to examine such constructs in different disciplines and with different student populations to examine replicability and to understand why low and high levels of teacher and parental autonomy support are associated with different values of HP and OP.

Results from this study also demonstrate that factors outside of students' studies (e.g., perceived parental autonomy support) impact their passion for their studies. These results are similar to findings obtained by Rahimi and Vallerand (in press) in which students' secondary passions (e.g., harmonious passion for a second activity outside of students' studies) positively influenced their positive emotions about their studies, which were negatively related with their academic procrastination. Thus, additional sources of autonomy support (e.g., friends, romantic partners, etc.) should also be investigated as potential determinants in the development of a passion for studies. Furthermore, these findings have practical implications for educators and caretakers, showing the vital function that students' environments play in fostering their passion. Therefore, this study underscores another avenue for future research wherein interventions can target training both teachers and parents on how to provide autonomy support to students (e.g., Cheon et al., 2020). 


\section{AUTONOMY SUPPORT AND PASSION IN EDUCATION}

The authors declare that there are no potential conflicts of interest with respect to the research, authorship, and publication of this article. 


\section{References}

Author 1 (blinded for review)

Author 2 (blinded for review)

Author 3 (blinded for review)

Author 4 (blinded review)

Bentzen, M. , Lemyre, P.-N. , \& Kenttä, G. (2016). Changes in motivation and burnout indices in high-performance coaches over the course of a competitive season. Journal of Applied Sport Psychology, 28(1), 28-48. https://doi.org/10.1080/10413200.2015.1053160

Black, A. E., \& Deci, E. L. (2000). The effects of students' self-regulation and instructor autonomy support on learning in a college-level natural science course: A selfdetermination theory perspective. Science Education, 84, 740-746.

Boiché, J., \& Caudroit, J. (2019). Passion Toward Work and Work-Life Conflict. In R. J. Vallerand \& N. Houlfort (Eds.). Passion for Work: Theory, Research, and Applications, (pp. 301-326). Oxford University Press.

Bonneville-Roussy, A., Lavigne, G. L., \& Vallerand, R. J. (2011). When passion leads to excellence: The case of musicians. Psychology of Music, 39(1), 123-138. https://doi.org/10.1177/0305735609352441

Bonneville-Roussy, A., Vallerand, R. J., \& Bouffard, T. (2013). The roles of autonomy support and harmonious and obsessive passions in educational persistence. Learning and Individual Differences, 24, 22-31. https://doi.org/10.1016/j.lindif.2012.12.015

Cheon, S. H., Reeve, J., \& Song, Y. G. (2019). Recommending goals and supporting needs: An intervention to help physical education teachers communicate their expectations while 
AUTONOMY SUPPORT AND PASSION IN EDUCATION

supporting students' psychological needs. Psychology of Sport and Exercise, 41, 107-

118. https://doi.org/10.1016/j.psychsport.2018.12.008

Cheon, S. H., Reeve, J., \& Vansteenkiste, M. (2020). When teachers learn how to provide classroom structure in an autonomy-supportive way: Benefits to teachers and their students. Teaching and Teacher Education, 90, 103004.

https://doi.org/10.1016/j.tate.2019.103004

Cohen, J., Cohen, P., West, S. G., \& Aiken, L. S. (2003). Applied multiple regression/correlation analysis for the behavioral sciences (3rd ed.). Lawrence Erlbaum Associates Publishers.

Curran, T., Appleton, P. R., Hill, A. P., \& Hall, H. K. (2013). The mediating role of psychological need satisfaction in relationships between types of passion for sport and athlete burnout. Journal of Sports Sciences, 31(6), 597-606. https://doi.org/10.1080/02640414.2012.742956

Curran, T., Hill, A. P., Appleton, P. R., Vallerand, R. J., \& Standage, M. (2015). The psychology of passion: A meta-analytical review of a decade of research on intrapersonal outcomes. Motivation and Emotion, 39(5), 631-655. https://doi.org/10.1007/s11031-015-9503-0

Deci, E. L., \& Ryan, R. M. (1987). The support of autonomy and the control of behavior. Journal of Personality and Social Psychology, 53(6), 1024-1037. https://doi.org/10.1037/0022-3514.53.6.1024

Deci, E. L., \& Ryan, R. M. (2000). The" what" and" why" of goal pursuits: Human needs and the self-determination of behavior. Psychological Inquiry, 11(4), 227-268. https://doi.org/10.1207/S15327965PLI1104_01

Franche, V., \& Gaudreau, P. (2016). Integrating dispositional perfectionism and within-person 
AUTONOMY SUPPORT AND PASSION IN EDUCATION

variations of perfectionism across life domains into a multilevel extension of the $2 \times 2$ model of perfectionism. Personality and Individual Differences, 89, 55-59. https://doi.org/10.1016/j.paid.2015.09.046

Fredricks, J. A., Alfeld, C., \& Eccles, J. (2010). Developing and fostering passion in academic and non-academic domains. Gifted Child Quarterly, 54(1), 18-30. https://doi.org/ $\underline{10.1177 / 0016986209352683}$

Gaudreau, P. (2012). A methodological note on the interactive and main effects of dualistic personality dimensions: An example using the $2 \times 2$ model of perfectionism. Personality and Individual Differences, 52(1), 26-31. https://doi.org/10.1016/j.paid.2011.08.022

Gaudreau, P., \& Thompson, A. (2010). Testing a quadripartite model of dispositional perfectionism. Personality and Individual Differences, 48, 532-537. https://doi.org/10.1016/j.paid.2009.11.031

Gaudreau, P., \& Verner-Filion, J. (2012). Dispositional perfectionism and well-being: A test of the $2 \times 2$ model of perfectionism in the sport domain. Sport, Exercise, and Performance Psychology, 1(1), 29-43. https://doi.org/10.1037/a0025747

Guay, F., Ratelle, C., Larose, S., Vallerand, R. J., \& Vitaro, F. (2013). The number of autonomysupportive relationships: Are more relationships better for motivation, perceived competence, and achievement? Contemporary Educational Psychology, 38, 375-382, http://dx.doi.org/10.1016/j.cedpsych.2013.07.005

Lietaert, S., Roorda, D., Laevers, F., Verschueren, K., \& De Fraine, B. (2015). The gender gap in student engagement: The role of teachers' autonomy support, structure, and involvement. British Journal of Educational Psychology, 85, 498-518. 
AUTONOMY SUPPORT AND PASSION IN EDUCATION

https://doi.org/10.1111/bjep.12095

Mageau, G. A., \& Vallerand, R. J. (2003). The coach-athlete relationship: A motivational model. Journal of sports science, 21(11), 883-904. https://doi.org/10.1080/0264041031000140374

Mageau, G.A., Vallerand, R. J., Charest, J., Salvy, S.-J., Lacaille, N., Bouffard. T., \& Koestner, R. (2009). On the development of harmonious and obsessive passion: The role of autonomy support, activity valuation, and identity processes. Journal of Personality, (Vol. 77, pp. 601-645). https://doi.org/10.1111/j.1467-6494.2009.00559

Oriol-Granado, X., Mendoza-Lira, M., Covarrubias-Apablaza, C. G., \& Molina-López, V. M. (2017). Positive emotions, autonomy support and academic performance of university students: The mediating role of academic engagement and self-efficacy. Revista de Psicodidáctica (English ed.), 22(1), 45-53. https://doi.org/10.1387/RevPsicodidact.14280

Patall, E. A., \& Zambrano, J. (2019). Facilitating student outcomes by supporting autonomy: Implications for practice and policy. Policy Insights from the Behavioral and Brain Sciences, 6(2), 115-122. https://doi.org/10.1177/2372732219862572

Patall, E. A., Steingut, R. R., Vasquez, A. C., Trimble, S. S., Pituch, K. A., \& Freeman, J. L. (2018). Daily autonomy supporting or thwarting and students' motivation and engagement in the high school science classroom. Journal of Educational Psychology, 110, 269. https://doi.org/10.1037/edu0000214

Philippe, F. L., Vallerand, R. J., \& Lavigne, G. L. (2009). Passion does make a difference in people's lives: A look at well-being in passionate and non-passionate individuals. Applied Psychology: Health and Well-Being, 1(1), 3-22. https://doi.org/10.1111/j.1758- 
AUTONOMY SUPPORT AND PASSION IN EDUCATION

$\underline{0854.2008 .01003 . \mathrm{x}}$

Philippe, F. L., Vallerand, R. J., Houlfort, N., Lavigne, G. L., \& Donahue, E. G. (2010). Passion for an activity and quality of interpersonal relationships: The mediating role of emotions. Journal of Personality and Social Psychology, 98(6), 917-932. https://doiorg.ezproxy.usherbrooke.ca/10.1037/a0018017

Raftery-Helmer, J. N. \& Grolnick, W. S. (2018). Parent and teacher effects on academic coping and classroom engagement: Testing a motivational model. Motivation and Emotion, 42, 638-652.https://doi.org/10.1007/s11031-018-9676-4

Ratelle, C. F., Larose, S., Guay, F., \& Senécal, C. (2005). Perceptions of parental involvement and support as predictors of college students' persistence in a science curriculum. Journal of Family Psychology, 19, 286-293. https://doi.org/10.1037/0893-3200.19.2.286

Ratelle, C. F., Simard, K., \& Guay, F. (2012). University students' subjective well-being: The role of autonomy support from parents, friends, and the romantic partner. Journal of Happiness Studies, 14, 893-910. https://doi.org/10.1007/s10902-012-9360-4

Reeve, J. (2006). Teachers as facilitators: What autonomy-supportive teachers do and why their students benefit. The Elementary School Journal, 106(3), 225-236. https://doi.org/10.1086/501484

Ruiz-Alfonso, Z., \& León, J. (2016). The role of passion in education: A systematic review. Educational Research Review, 19, 173-188. https://doi.org/10.1016/j.edurev.2016.09.001

Ruiz-Alfonso, Z., Vega, L. S., \& Beltran, E. V. (2018). What about passion in education? The concept of passion, why it is important and how teachers can promote it. European Scientific Journal, 14(1), 19-28. https://doi.org/10.19044/esj.2018.v14n1p19 
Ryan, R. M., \& Deci, E. L. (2000). Self-determination theory and the facilitation of intrinsic motivation, social development, and well-being. American psychologist, 55(1), 68. https://doi.org/10.1006/ceps.1999.1020

Schellenberg, B. J. I., \& Bailis, D. S. (2015). Predicting longitudinal trajectories of academic passion in first-year university students. Learning and Individual Differences, 40, 149155. https://doi.org/10.1016/j.lindif.2015.04.008

Schellenberg, B. J., \& Bailis, D. S. (2017). Lay theories of passion in the academic domain. Educational Psychology, 37(9), 1029-1043. https://doi.org/10.1080/01443410.2017.1322178

Schellenberg, B. J. I., Verner-Filion, J., Gaudreau, P., Bailis, D. S., Lafrenière, A. K., \& Vallerand, R. J. (2018). Testing the Dualistic Model of Passion using a novel quadripartite approach: A look at physical and psychological well-being. Journal of Personality, 87(2), 163-180. https://doi.org/10.1111/jopy.12378

Slemp, G. R., Lee, M. A., \& Mossman, L. H. (2021). Interventions to support autonomy, competence, and relatedness needs in organizations: A systematic review with recommendations for research and practice. Journal of Occupational and Organizational Psychology, 1-31. https://doi.org/10.1111/joop.12338

Tóth-Király, I., Bőthe, B., Gál, É., Orosz, G., \& Rigó, A. (2021). Perceived Parenting Practices as Predictors of Harmonious and Obsessive Passion Among High Schoolers and Adults. Journal of Happiness Studies, 1-19. https://doi.org/10.1007/s10902-021-00355-8

Vallerand, R. J. (2008). On the psychology of passion: In search of what makes people's lives 
AUTONOMY SUPPORT AND PASSION IN EDUCATION

most worth living. Canadian Psychology/Psychologie canadienne, 49(1), 1-13. https://doi.org/10.1037/0708-5591.49.1.1

Vallerand, R. J. (2010). On passion for life activities: The dualistic model of passion. In M.P. Zanna (Ed.). Advances in Experimental Social Psychology, (Vol. 42, pp. 97-193). Academic Press. https://doi.org/10.1016/S0065-2601(10)42003-1

Vallerand, R. J. (2015). The psychology of passion: A dualistic model. (R. J. Vallerand, Ed.). Oxford University Press. https://doi.org/10.7202/1041845ar

Vallerand, R. J. (2016). The Dualistic Model of Passion: Theory, research, and implications for the field of education. In J. C. K. Wang, L.W. Chia, \& R.M. Ryan (Eds.). Building autonomous leaders: Research and practical perspectives using Self-Determination Theory. Springer.

Vallerand, R. J., Blanchard, C. M., Mageau, G. A., Koestner, R., Ratelle, C. F., Léonard, M.,...Marsolais, J. (2003). Les passions de l'âme: On obsessive and harmonious passion. Journal of Personality and Social Psychology, 85, 756-767. https://doi.org/10.1037/0022$\underline{3514.85 .4 .756}$

Vallerand, R. J., Mageau, G. A., Elliot, A. J., Dumais, A., Demers, M. A., \& Rousseau, F. (2008). Passion and performance attainment in sport. Psychology of Sport and Exercise, 9(3), 373-392. https://doi.org/10.1016/j.psychsport.2007.05.003

Vallerand, R. J., Salvy, S. J., Mageau, G. A., Elliot, A. J., Denis, P., Grouzet, F. M. E., \& Blanchard, C. B. (2007). On the role of passion in performance. Journal of personality, 75(3), 505-534. https://doi.org/10.1111/j.1467-6494.2007.00447.x

Vasquez, A. C., Patall, E. A., Fong, C. J., Corrigan, A. S., \& Pine, L. (2015). Parent autonomy 


\section{AUTONOMY SUPPORT AND PASSION IN EDUCATION}

support, academic achievement, and psychosocial functioning: A meta-analysis of research. Educational Psychology Review, 28, 605-644. https://doi.org/10.1007/s10648-

$\underline{015-9329-Z}$ 
Table 1

Four Levels of Teacher and Parental Autonomy Support

Teacher Autonomy Support (TAS)

\begin{tabular}{cccc}
\hline & & Low & High \\
\cline { 3 - 3 } Parental Autonomy & Low & Low Support (LS) & Pure TAS (PT) \\
\cline { 3 - 4 } Support (PAS) & High & Pure PAS (PP) & Dual Support (DS) \\
\hline
\end{tabular}


Table 2

Correlations and Descriptive Statistics Between Autonomy Support and Passion

\begin{tabular}{lcccc}
\hline & TAS & PAS & HP & OP \\
\hline TAS & $3.20(0.91)$ & & & \\
PAS & $0.07^{*}$ & $4.25(0.83)$ & & \\
HP & $0.28^{* * *}$ & $0.16^{* * *}$ & $3.27(0.82)$ & \\
OP & $0.20^{* * *}$ & -0.02 & $0.51^{* * *}$ & $2.19(0.80)$ \\
\hline
\end{tabular}

$* p<.05, * * p<.01, * * * p<.001$

TAS: Teacher Autonomy Support

PAS: Parental Autonomy Support

HP: Harmonious Passion

OP: Obsessive Passion 
Table 3

Planned Comparisons of High and Low Levels of Teacher and Parental Autonomy Support

\begin{tabular}{ccc}
\hline Planned contrasts & Cohen's d (HP) & Cohen's d (OP) \\
\hline PT vs PP & 0.24 & 0.43 \\
PT vs DS & 0.29 & 0.04 \\
PT vs LS & 0.54 & 0.39 \\
PP vs DS & 0.54 & 0.39 \\
PP vs LS & 0.29 & 0.04 \\
DS vs LS & 0.83 & 0.35 \\
\hline
\end{tabular}

LS: Low Support

DS: Dual Support

PT: Pure Teacher

PP: Pure Parent 
Figure / Figure 1

Figure 1

Main Effects of Teacher and Parental Autonomy Support on Harmonious Passion

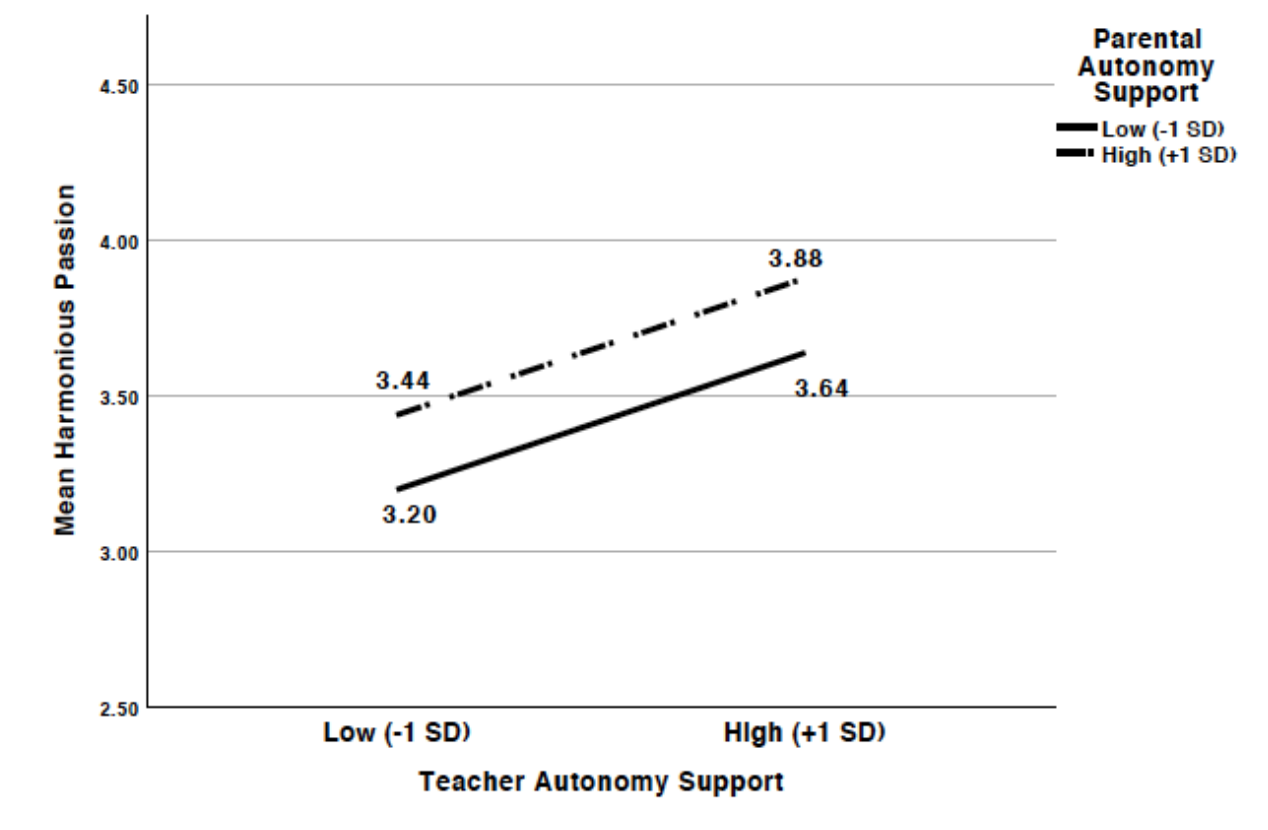
Autonomy

Support

High (+1 SD)

Teacher Autonomy Support 
Figure / Figure 2

Figure 2

Main Effects of Teacher and Parental Autonomy Support on Obsessive Passion

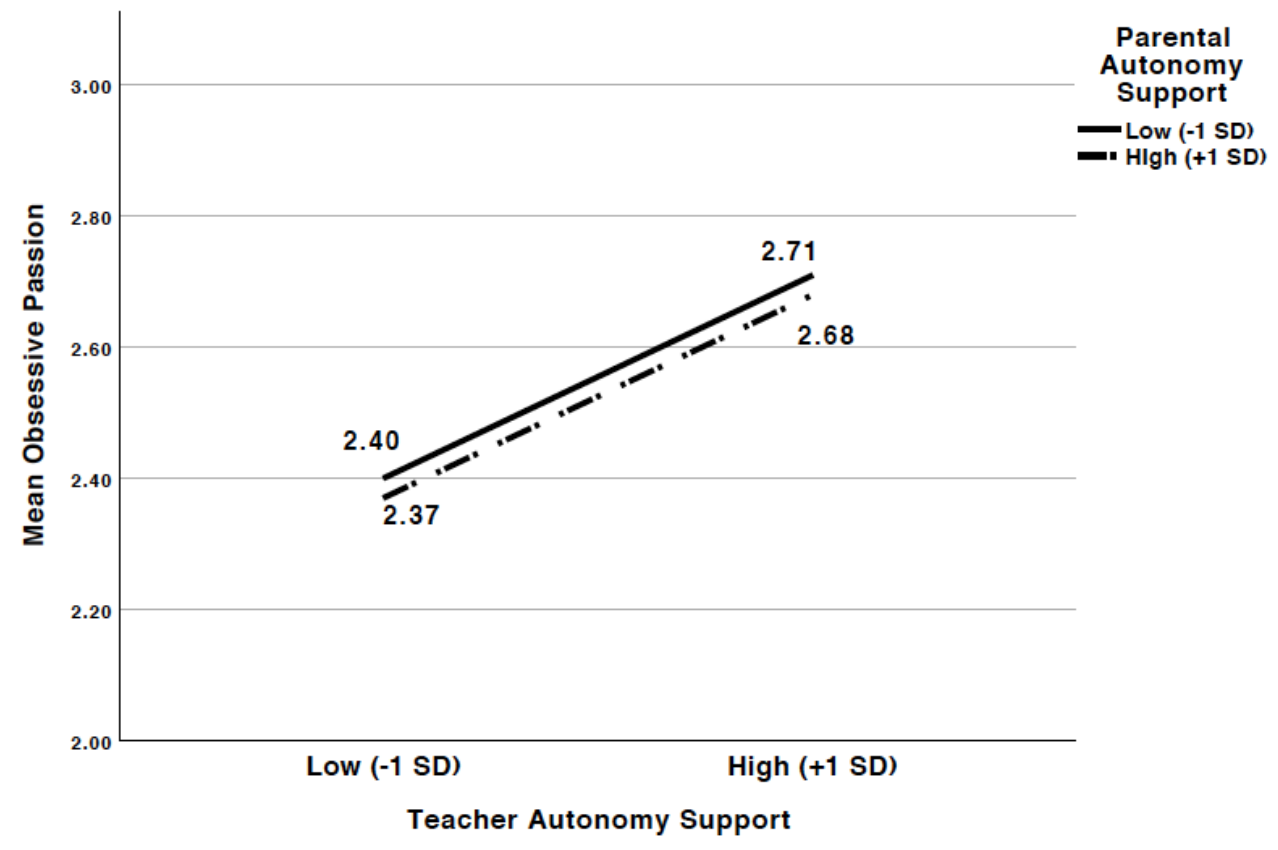
Support

Low (-1 SD)
Low (-1 SD)
High (+1 SD)
Teacher Autonomy Support 